\title{
Usability Testing of a Metasearch Interface: A Case Study
}

\section{Laura Wrubel and Kari Schmidt}

This study evaluated the usability of a metasearch, or federated search, interface used by the University System of Maryland and Affiliated Institutions. The authors conducted usability testing of the metasearch system to understand student perceptions of metasearch's usefulness and to learn if students could effectively complete research tasks using metasearch. Students determined when they had successfully completed the task. The study found that students perceived metasearch to be a useful tool but that they had low rates of success in completing some tasks. Technical limitations and interface design problems contributed to their difficulties. Students expected to be able to construct searches as they do in Internet search engines and, for example, expected results lists to have relevancy ranking and more descriptive information.

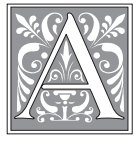

s libraries offer their users expanding collections of electronic resources, including databases, online journals, and e-books, metasearch systems have become increasingly appealing. Also sometimes referred to as federated search, metasearch promises users the ability to search across multiple databases at the same time, reducing the burden of learning many different search interfaces and, thereby, streamlining research.

The 16 libraries in the University System of Maryland and Affiliated Institutions (USMAI) share an implementation of Ex Libris' MetaLib metasearch system. At the time of the study, USMAI had implemented MetaLib version 3.12. The interface, named Research Port, provides two differently configured metasearch options: Quick Search and Cross Search. Quick Search allows users to search a small set of databases preselected by librarians. Cross Search allows users to select a subject category and subcategory and then databases within that subcategory to include in the search. Both search screens present one search box, although each has an "Advanced" tab users can select to do fielded searching on a limited set of fields.

Because it aggregates search results from multiple sources, metasearch can take longer to present results than a single database or an Internet search engine. Technical limitations influence the functionality of metasearch, so libraries should take advantage of opportunities to customize these interfaces to make them as usable as possible. ${ }^{1}$ During the development of Research Port, these challenges

Laura Wrubel is Systems Librarian in the University of Maryland Libraries; e-mail: lwrubel@umd.edu. Kari Schmidt is Collection Management E Electronic Resources Librarian in the Dahlgren Memorial Library at Georgetown University; e-mail: kbs8@georgetown.edu. Funding for this study was provided by the University of Maryland Libraries. The authors would like to thank Jennie Callas for her assistance in transcribing videos. 
were a concern and librarians wondered about students' ability to understand and knowledgeably use such a tool. The following questions arose:

- Are students able to effectively use metasearch tools to accomplish research tasks?

- What are students' perceptions of the usefulness of metasearch?

To help answer these questions, the investigators conducted usability testing on the Quick Search and Cross Search metasearch screens at four institutions in USMAI.

\section{Review of the Literature}

Usability testing is an established and accepted practice for evaluating library Web sites, such as OPACs, homepages, and portals. ${ }^{2}$ As part of a user-centered design process that engages real users with real tasks, usability testing provides both quantitative and qualitative data. ${ }^{3}$ In published usability studies conducted at university libraries, quantitative data such as task completion rates and timing of tasks supplements rich qualitative data gathered from recordings of participant behavior and verbal commentary.

Steve Brantley, Annie Armstrong, and Krystal Lewis conducted usability testing on a customizable library portal at the University of Illinois at Chicago to assess the portal's ease of use and students' interest in using its customization features. ${ }^{4}$ Their test consisted of a series of 19 tasks administered to eight participants. The investigators used quantitative measures such as task completion rates, time to complete tasks, and number of actions. Qualitative data, such as user comments, was useful in identifying navigation and layout problems, evaluating ease of use, and assessing user comprehension. They identified problems with the site's descriptive language, which reflected library definitions instead of those used more commonly on the Web. Following common Web design and navigation conventions was shown to be important. In a previous usability study on the library
Web site at that institution, investigators had found problems with categories and labels on the site and found that students' ability to use the site was, in part, affected by their "lack of understanding and awareness of library resources." ${ }^{\prime 5}$

Another academic library, at the University of Mississippi, carried out a "usability survey" as part of an ongoing assessment of its library homepage. ${ }^{6}$ In the survey, each of the twelve participants was asked to complete eight tasks on the library Web site. The researchers measured the number of clicks to accomplish each task, time per task, user satisfaction, and qualitative data such as user signs of frustration or indecision and comments by both the participant and the test observer. Leanne VandeCreek's usability analysis at Northern Illinois University Libraries encompassed usability testing, focus groups, and surveys. ${ }^{7}$ Although the researchers measured basic task completion rates, they also measured "success with qualifications," as users often complete tasks, but do so in a circuitous way. Analysis of qualitative data showed that poor site navigation and participants' lack of information literacy skills contributed to the difficulties they experienced in the site.

There have been fewer published usability studies of library federated search tools. Susan Elliott reviewed the state of metasearch systems and observed usability testing and focus group research at three institutions. ${ }^{8}$ She identified several areas of concern: navigation, lack of adherence to Web standards, difficulties with choice of databases and search options, system feedback during the search progress, and display of results. Users were overwhelmed by the number of choices offered within the interface and found it difficult to access full-text content. Novice users encountered difficulties in deciding which databases to search and had trouble with library terminology presented on advanced search screens. Elliott calls for "a great deal more research into the needs and information-seeking habits of library users" because "while libraries 
are indeed conducting usability testing and other types of user studies, it is clear that librarian preferences rather than user preferences still rule the design of libraryoriented metasearch tools."

Another study of metasearch also raised issues concerning functionality and interface design. One of the first institutions to implement MetaLib and involved users in its design was Boston College. The library used a beta test to solicit faculty and student opinions about the metasearch interface. ${ }^{10}$ Twenty faculty and graduate students completed an online survey and attended a focus group about the portal. Bob Gerrity, Theresa Lyman, and Ed Tallent found that some users were frustrated with the lack of search complexity possible in the interface and the limited citation information presented in search results. ${ }^{11}$ In further usability testing in 2003, Tallent found that users want simple interfaces that allow keyword searching. ${ }^{12}$ They want to start searching immediately, will ignore instructions or other lengthy text, and, as Elliott found, they have difficulty selecting databases to search.

\section{Usability Methodology}

In a formal usability test, "end users complete a set of real tasks while test observers collect information on behavior, expectations, and other empirical data."13 During the usability test, a facilitator, ideally a neutral party not directly involved in the design and management of the Web site, will present a list of tasks to a participant. The participant will then try to use the Web site to accomplish each task. As the test progresses, the participant will be asked to speak his or her thoughts and reactions aloud. Approaches to usability testing may vary, but the "think aloud" protocol described above, where participants use the site while they describe their experience out loud, offers a balance of efficiency and quantity of data gathered. ${ }^{14}$ The facilitator prompts the participant to explain his or her actions and expectations in the site while avoiding any tendency to lead the user.

In this study, the researchers conducted observation-based formal usability testing on students at four campuses in USMAI between late spring 2005 and early 2006 . According to Jakob Nielsen, as few as

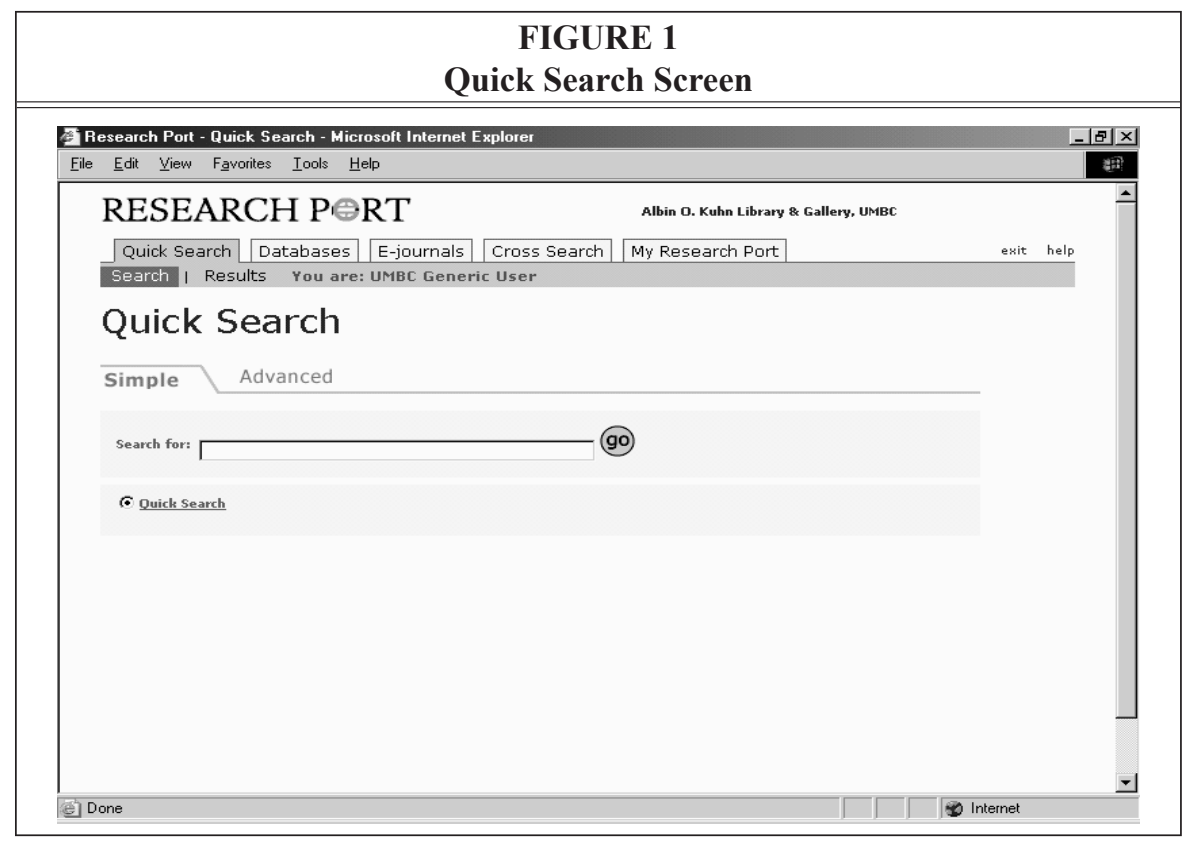


five participants can discover $85 \%$ of the problems with a particular site and at least 15 users are needed to discover all usability problems on the pages being tested. ${ }^{15}$ Because of the number of locations included in the study and the desire to fully investigate the range of usability problems, the investigators used a convenience sample of 18 students. This number is in line with other published library usability studies. ${ }^{16}$ Although subjects were at different campuses, all used the same campus's metasearch interface, containing a consistent set of databases and subject categories.

In each session, the participant was presented with a set of topics to begin researching in Research Port's Quick Search and Cross Search pages. Each question required students to locate two articles or books that would be useful in researching the topic provided. The investigators reviewed sample test questions and paper topics on course Web sites to design tasks that were similar to assignments students may encounter. In each section of the test, one question was to be completed by all participants and then the participants were offered three options for the second task. This allowed students to select a topic more familiar to them and to avoid having their lack of knowledge or interest in a subject interfere with their ability to complete the task.

One of the researchers acted as a monitor during the test, encouraging participants to talk aloud during the session, prompting them to explain what they expected the interface to do with each option they clicked on. TechSmith's Morae software was used with a Web camera to record screen display and mouse movement, participants' verbal comments, and nonverbal reactions. Each session lasted approximately 45-60 minutes.

Students were recruited within study areas in the library, using a flyer that was distributed describing the project. Each participant received a bookstore gift certificate as compensation. The investigators received human subjects approval from the University of Maryland's Institutional Review Board. All participants signed informed consent forms describing

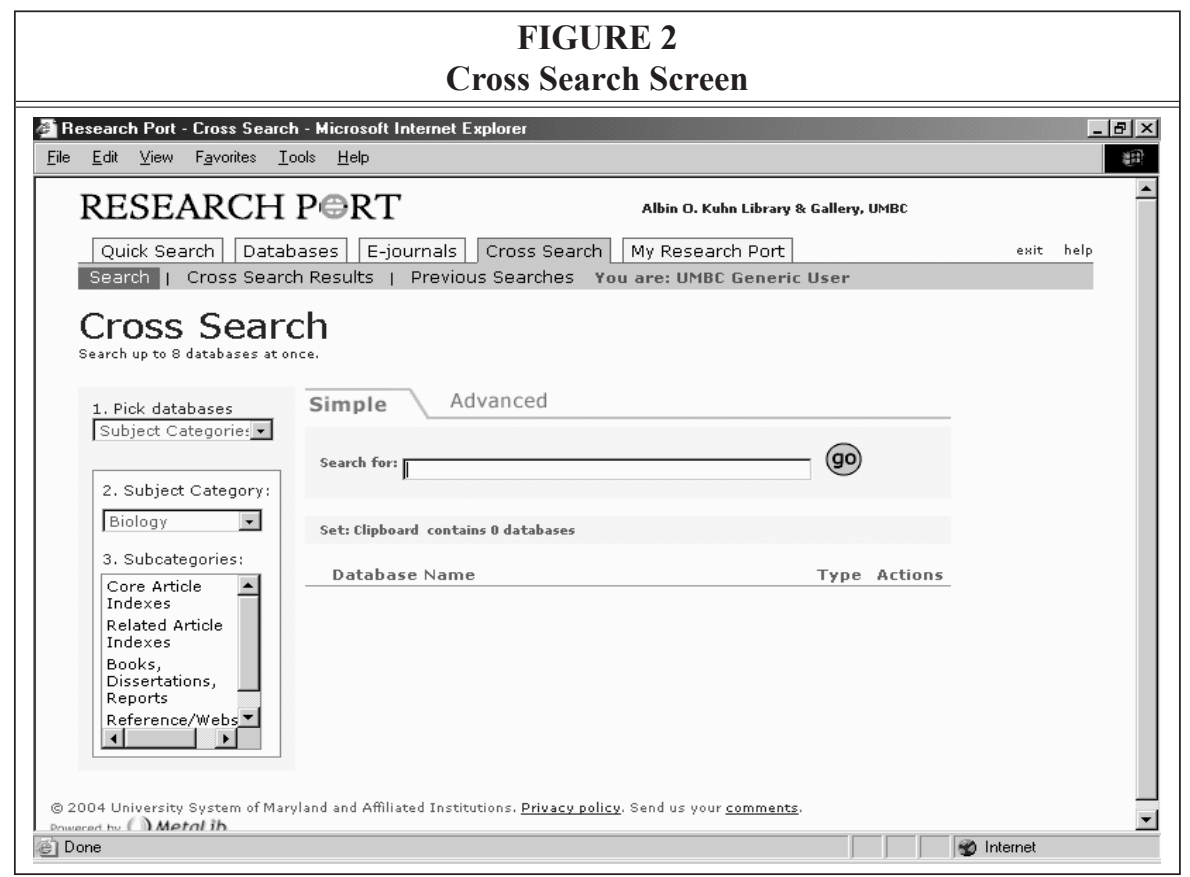


the testing process and how data would be shared.

\section{Data Analysis}

The observation-based usability protocol described above gathered both qualitative and quantitative data. Video and audio footage of each usability test was recorded. With funds granted by the University of Maryland Library Faculty Research Fund, a graduate student from the University of Maryland's College of Information Studies was hired to transcribe the footage. Transcription involved capturing all verbal comments, nonverbal indications such as pointing at the screen or nodding of the head, and screen actions. Screen actions, such as clicks and menu selections, were noted in the transcript and the page on which the action occurred was recorded. For example, when a student was at the Cross Search search page, his or her search terms, database subject category choice, and subcategory choice were all transcribed.

The investigators coded the transcripts using the constant comparative method of analysis, whereby the verbal comments, nonverbal comments, and screen actions were categorized into a coding structure based on three broad themes defined by the investigators during an initial review of the transcripts: perceptions, searching and navigation, and design and display of information. ${ }^{17}$ Each investigator independently coded the first two tests to generate codes within the broad themes. The investigators compared, reconciled, and modified their individual codes together to come up with a standard code structure. The investigators then independently recoded the first two tests using the standard set of codes and ran an intercoder check, which showed an agreement of 81 percent. Using the intercoder check, the investigators were able to resolve all coding conflicts and refine the code structure for consistency and accuracy. The remaining transcripts were divided between the investigators and any new codes were iteratively added or adapted to accommodate new trends. Previously coded transcripts were reviewed when these additions and adaptations to the codes occurred. Some codes were recategorized based on overall theme, although this did not affect data tabulation or assignment.

The first task tested on the Quick Search page was the same for all participants, as was the first task on the Cross Search interface. The first tasks were broad and interdisciplinary in scope. The second task on each interface, however, offered students the choice between three different types of questions, which were more subject oriented. A task was recorded as completed when the participant so indicated.

Investigators measured completion, or success, as defined by participants. If students found citations they felt met the need described in the task, the students were considered to have successfully completed the task. Task completion was described as successful, partially successful, or unsuccessful for each participant per question. Successful completion was recorded only when participants found the required number of items and deemed them acceptable. Investigators considered a task partially successful when participants did not find the number of items specified in the task but did find at least one useful item, or when participants judged the search results generally acceptable but did not identify particular items they would use. A task was considered unsuccessfully completed when participants did not find search results useful, felt they could not answer a question using metasearch, or ran into technical difficulties from which they could not recover. In many of these instances, students declared they were unable to complete the task using either Quick Search or Cross Search.

\section{Results \\ Demographic Overview}

Eighteen undergraduates participated in the usability testing. The students were 


\begin{tabular}{|l|r|c|}
\hline \multicolumn{3}{|c|}{ TABLE 1 } \\
\hline \multicolumn{2}{|c|}{ Student Perceptions of Metasearch } \\
\hline \hline Quick Search & n $=18$ & $\%$ \\
\hline Perceived QS is for simple/broad searches & 13 & $72.22 \%$ \\
\hline Perceived QS simultaneously searches multiple databases & 12 & $66.67 \%$ \\
\hline Perceived speed that results returned as reasonable & 8 & $44.44 \%$ \\
\hline Assumed QS is a fast search (i.e., executed quickly) & 7 & $38.89 \%$ \\
\hline Perceived QS is a research starting point & 6 & $33.33 \%$ \\
\hline Perceived speed that results returned as too slow & 5 & $27.78 \%$ \\
\hline Cross Search & 9 & $50.00 \%$ \\
\hline Assumed CS provides more search complexity & 8 & $44.44 \%$ \\
\hline $\begin{array}{l}\text { Perceived that continuing to use metasearch will not help them com- } \\
\text { plete the task; would go to alternative resources (Internet or librarian) }\end{array}$ & 7 & $38.89 \%$ \\
\hline Perceived that CS searches multiple databases within a subject category & 7 \\
\hline
\end{tabular}

composed of nine juniors, six seniors, two sophomores, and one freshman. Academic majors ranged from dance to biology, with nine reporting a major in the social sciences, seven in the humanities, and three in the sciences. All participants stated they had used the library's Web site to conduct research for their classes, with half reporting familiarity with Research Port. All but three said they used Internet resources other than the library's to conduct research, with 13 citing use of either Google or Yahoo as preferred search engines.

\section{Perceptions of Metasearch Quick Search}

Thirteen participants perceived Quick Search as a mechanism that allowed for simple or broad searching. Of these 13 students, nine also understood the search to be a simultaneous search of multiple databases, with twelve of the total participants comprehending this functionality. Seven students felt Quick Search meant a "fast" search and six participants regarded it as a place to begin their research. Eight students measured the speed of the search processing as reasonable and only five found the system too slow.

\section{Cross Search}

Half of the undergraduates perceived that Cross Search provided a more com- plex search and seven understood that it allowed multiple databases within a subject category to be searched at once. Once they had tried using Cross Search, almost half of participants, eight in total, felt that, if they continued to use Cross Search, it would not help them answer at least one of the test questions. They said they would abandon the system and go elsewhere to answer the question.

\section{Searching \& Navigation Quick Search}

The most frequent behavior observed during testing in Quick Search was the participants forming search statements composed of lengthy text strings. These searches often incorporated multiple concepts and/or phrases, sometimes directly from the text of the question, without the use of Boolean operators (for instance, "school uniforms public schools"). Fourteen students searched using this type of statement. Nine of the students modified their search statements from broad to specific and five from specific to broad when the results from Quick Search were found unacceptable. Some students used a broad search to find what they called "catchphrases," "strings," or "research words" to use as search terms in a more precise search. Six students noted the presence of the advanced search option 
in Quick Search, but none ultimately selected and used it.

Students regularly navigated through Quick Search using the browser's Back button, instead of system-provided navigational links. While half used the toolbar's search link, eight students used the browser back link to return to the main Quick Search screen. In the course of using the Back button, they encountered unexpected screens or metasearch behavior. This unexpected system behavior also occurred when they used Quick Search's previous or next links. Half also used the "results list" link to maneuver among returned results.

\begin{tabular}{|c|c|c|}
\hline \multicolumn{3}{|l|}{$\begin{array}{c}\text { TABLE } 2 \\
\text { Searching \& Navigation in Metasearch }\end{array}$} \\
\hline Quick Search & $\mathrm{n}=\mathbf{1 8}$ & $\%$ \\
\hline $\begin{array}{l}\text { Entered search statement as a string of words and/or phrases describ- } \\
\text { ing multiple concepts }\end{array}$ & 14 & $77.78 \%$ \\
\hline Used Find It button & 11 & $61.11 \%$ \\
\hline Modified search from broad to specific & 9 & $50.00 \%$ \\
\hline Used search link or tab in toolbar & 9 & $50.00 \%$ \\
\hline Used results list link to navigate among results & 9 & $50.00 \%$ \\
\hline Assumed full-text sometimes (not always) available through Find It & 7 & $38.89 \%$ \\
\hline Used browser "Back" button to return to search screen from results list & 8 & $44.44 \%$ \\
\hline $\begin{array}{l}\text { Used Previous or Next or browser "Back" and given unexpected } \\
\text { results when navigating among results list views (table, brief, full } \\
\text { record) }\end{array}$ & 8 & $44.44 \%$ \\
\hline Commented on Advanced Search tab but did not use it & 6 & $33.33 \%$ \\
\hline Modified search from specific to broad & 5 & $27.78 \%$ \\
\hline \multicolumn{3}{|l|}{ Cross Search } \\
\hline Selected subject category & 16 & $88.89 \%$ \\
\hline Liked ability to choose subject categories & 14 & $77.78 \%$ \\
\hline Changed subject category or subcategory & 10 & $55.56 \%$ \\
\hline Used search link or tab in toolbar & 9 & $50.00 \%$ \\
\hline Used results list link to navigate among results & 9 & $50.00 \%$ \\
\hline Selected subcategory within subject category & 8 & $44.44 \%$ \\
\hline $\begin{array}{l}\text { Entered search statement as a string of words and/or phrases describ- } \\
\text { ing multiple concepts }\end{array}$ & 8 & $44.44 \%$ \\
\hline Expressed that left column labels unclear & 7 & $38.89 \%$ \\
\hline Expressed confusion over subcategory names and/or which to select & 7 & $38.89 \%$ \\
\hline Used Find It button & 7 & $38.89 \%$ \\
\hline Modified search from broad to specific & 6 & $33.33 \%$ \\
\hline $\begin{array}{l}\text { Used Previous or Next or browser "Back" and given unexpected } \\
\text { results when navigating among results list views (table, brief, full } \\
\text { record) }\end{array}$ & 6 & $33.33 \%$ \\
\hline Clicked on link to database from results list or full record & 6 & $33.33 \%$ \\
\hline Liked ability to select/deselect databases within subject category & 5 & $27.78 \%$ \\
\hline
\end{tabular}


Also prevalent was the use of the "Find It" link resolver button, with 11 students clicking on the link. Seven students understood that full text may be available through Find It.

\section{Cross Search}

In Cross Search, where databases are grouped by subject category and then into subcategories, over three quarters of students were pleased with the ability to select categories. Five liked being able to choose or deselect databases within their chosen category. Workflow and navigation of the Cross Search screen perplexed students, with seven students mentioning that the category labels were unclear and another seven conveying confusion over the subcategorization.

Almost all participants, 16 in total, selected a subject category when beginning their search in Cross Search, with

\begin{tabular}{|c|c|c|}
\hline \multicolumn{3}{|l|}{$\begin{array}{c}\text { TABLE } 3 \\
\text { Design and Display of Information in Metasearch }\end{array}$} \\
\hline Quick Search & $\mathrm{n}=\mathbf{1 8}$ & $\%$ \\
\hline Liked presence of abstract & 10 & $55.56 \%$ \\
\hline Expected large results list & 9 & $50.00 \%$ \\
\hline Perceived recent items as more useful & 8 & $44.44 \%$ \\
\hline $\begin{array}{l}\text { Expected to be able to discern scholarly and nonscholarly items from } \\
\text { results display }\end{array}$ & 8 & $44.44 \%$ \\
\hline Liked presence of year in results table view & 8 & $44.44 \%$ \\
\hline Desired that results list display abstract & 8 & $44.44 \%$ \\
\hline $\begin{array}{l}\text { Found that some information on full record view was unnecessary or } \\
\text { unclear }\end{array}$ & 7 & $38.89 \%$ \\
\hline Made positive comment about QS interface & 7 & $38.89 \%$ \\
\hline Expected to be able to discern format type (article or book) & 6 & $33.33 \%$ \\
\hline Liked presence of title in results table view & 6 & $33.33 \%$ \\
\hline Liked highlighted search terms in results list & 6 & $33.33 \%$ \\
\hline Desired full-text in full record view & 5 & $27.78 \%$ \\
\hline Assumed results list sorted by date & 5 & $27.78 \%$ \\
\hline \multicolumn{3}{|l|}{ Cross Search } \\
\hline Made positive comment about CS interface & 7 & $38.89 \%$ \\
\hline $\begin{array}{l}\text { Found that some information on full record view is unnecessary or } \\
\text { unclear }\end{array}$ & 6 & $33.33 \%$ \\
\hline Liked presence of abstract & 6 & $33.33 \%$ \\
\hline Made positive comment about a native interface of another database & 6 & $33.33 \%$ \\
\hline Expected to be able to discern format type (article or book) & 6 & $33.33 \%$ \\
\hline Perceived recent items as more useful & 5 & $27.78 \%$ \\
\hline Liked presence of title in results table view & 5 & $27.78 \%$ \\
\hline Desired that results list display format in table view & 5 & $27.78 \%$ \\
\hline $\begin{array}{l}\text { Expressed that there are too many steps to get what is needed (too } \\
\text { much clicking) }\end{array}$ & 5 & $27.78 \%$ \\
\hline Made negative comment about CS interface & 5 & $27.78 \%$ \\
\hline
\end{tabular}


ten also changing the subject category or subcategory during the search process and eight selecting a subcategory within a subject category. Half of the students used the search link in the toolbar to return to the main search screen, and half also used the results list link to progress through results. Almost half, eight in total, formed search strings from the test questions. Seven students clicked on the Find It link for various reasons.

As in Quick Search, a third of the students modified their search statements to make them more specific. Also similar to Quick Search, a third experienced problems when using the browser's back feature or the system's previous or next links. In addition, a third clicked into an outside vendor database from a results record or results display mode.

\section{Design and Display of Information in Metasearch \\ Quick Search}

Overall, seven of the 18 students said they liked the Quick Search interface. While reviewing Quick Search's results list display, nine students expected a large set of results for their search. Eight students said they thought recent items were more useful and eight found the presence of year information helpful in making decisions about an item's usefulness. Six students made positive comments regarding the system's ability to highlight their search terms. Eight students expected the results list to indicate whether an item was scholarly, eight articulated a desire for inclusion of an abstract, and six expected to be able to discern format type.

After selecting a record, a little more than half of the participants, ten in all, expressed positive comments about the presence of an abstract, when available, and six liked that the titles were included on records. Said one student, "If there's no abstract, I would not even bother. If you have no abstract, I don't really want to read the rest of the paper because I don't know what it's about."
Not all records selected by participants had full text available, but five students who found full text asked that, when available, full text be part of the full record view. A considerable number of students, seven in all, felt there was extraneous or unclear data on the full records.

\section{Cross Search}

Overall, seven students expressed positive comments about the Cross Search interface and five had negative comments. In Cross Search, five students felt recent items were more useful than dated results, five commented on the helpfulness of item titles, and five requested that format type be part of the results view. Comments on the full record view were similar to those in Quick Search. A third of the students expected format type to be included and a third felt that abstracts, when available, were always helpful. Participants were dissatisfied with the full record display, with six finding some information ambiguous or confusing. Interestingly, a third talked positively and with familiarity about the search interfaces of vendor databases, such as EBSCOhost and JSTOR, in comparison to the Cross Search interface.

\section{Metasearch Task Completion}

Students generally fared better when using the Quick Search interface to complete tasks than the Cross Search interface. Using Quick Search, half of the students (nine) completed the first task successfully, five were partially successful, and four students were unable to complete the first task. However, completion rates on the second Quick Search task declined slightly, with eight students successful, four partially successful, and six unable to complete the task. The completion rates for the first task on the Cross Search interface were similar to the success rates in Quick Search. Half of the students were successful in completing the first task in Cross Search, with four partially successful and five unsuccessful. In the second Cross Search task, there was a 


\begin{tabular}{|c|c|c|}
\hline \multicolumn{3}{|c|}{$\begin{array}{c}\text { TABLE } 4 \\
\text { Metasearch Task Completion }\end{array}$} \\
\hline & $n=18$ & $\%$ \\
\hline \multicolumn{3}{|l|}{ QS Task 1} \\
\hline Successful & 9 & $50 \%$ \\
\hline Partially successful & 5 & $28 \%$ \\
\hline Unsuccessful & 4 & $22 \%$ \\
\hline \multicolumn{3}{|l|}{ QS Task 2} \\
\hline Successful & 8 & $44 \%$ \\
\hline Partially successful & 4 & $22 \%$ \\
\hline Unsuccessful & 6 & $33 \%$ \\
\hline \multicolumn{3}{|l|}{ CS Task 1} \\
\hline Successful & 9 & $50 \%$ \\
\hline Partially successful & 4 & $22 \%$ \\
\hline Unsuccessful & 5 & $28 \%$ \\
\hline \multicolumn{3}{|l|}{ CS Task 2} \\
\hline Successful & 4 & $22 \%$ \\
\hline Partially successful & 3 & $17 \%$ \\
\hline Unsuccessful & 11 & $61 \%$ \\
\hline $\begin{array}{l}\text { Would you use Quick } \\
\text { Search again? (Yes) }\end{array}$ & 17 & $94 \%$ \\
\hline $\begin{array}{l}\text { Would you use Cross } \\
\text { Search again? (Yes) }\end{array}$ & 9 & $50 \%$ \\
\hline
\end{tabular}

substantially higher rate of unsuccessful completion. More than half of the students, eleven in total, were unable to complete the second task in Cross Search, with only four students able to successfully complete the task and another three partially successful. After each participant finished the four tasks, the facilitator asked if he or she would use each interface again. Seventeen students said they would use Quick Search and nine students said they would use Cross Search for future research.

\section{Discussion}

\section{Success in Metasearch}

The completion rates demonstrate that both interfaces were difficult for the students to learn. As they used the interface during the test, their completion rates did not improve, as one might expect. The completion rates for the second task in Cross Search, in particular, illustrate this trend. At this point in the testing process, the students, on average, had been working with the system for a half hour, yet only four judged what they retrieved as successful and 11 could not complete their chosen task. Interestingly, the Cross Search interface is the most customized component of Research Port, with subject categories and subcategories defined by librarians and set up with the intent of fostering more precise searching and retrieval.

The researchers did not intentionally set up the tasks with the objective of making them increasingly challenging; rather, the aim was to allow for choices that mirrored real-world assignments and better aligned with potential participants' major area of study. The students seemed to find these more complex assignments difficult, and the majority of students could not complete the last task. However, they did not abandon Cross Search hastily. They executed multiple searches, selected and deselected subject categories, and felt Cross Search had the potential to be useful.

Poorer completion rates could be attributed in part to technical challenges. Some of the categories students selected had a limited number of cross-searchable databases, and some students received system error messages when searches failed because of configuration problems at the library or vendor end. In comparison, Quick Search is set up to search interdisciplinary databases, ensuring at least some success at search and retrieval on most topics.

Even with their uncertainties over how to use the Cross Search screen, students often commented that they liked the ability to choose subject categories. Students made use of the subject categories-almost all of the participants selected a subject category and more than half returned to the search screen to select different categories as they changed their 
search strategy. Confusion and poor task completion rates in Cross Search seemed to spring from interface workflow, navigation problems, and issues with subject categorization. Some students had difficulty identifying an appropriate category. One student said, "I should be looking under everything? ... For me, it just wasn't intuitive. It could be History, it could be Engineering stuff, it could be in all kinds of different things." Another student said, "I don't really understand how these broad subject categories can be useful for specific instances of information."

An equal number of participants said they liked the Cross Search interface as those who liked the Quick Search interface. However, students did say they would use Quick Search again at higher rates, not because of their perceptions or expectations of what it should or could do, but because of easier design and workflow, as well as problems with search and navigation errors in Cross Search. Although participants expressed frustration with the Cross Search interface and low success rates while using it, half said that they would use it again and seemed to find the resource potentially useful to them.

\section{Interface Implications}

Several global usability problems discovered in this testing have implications for designing metasearch interfaces. Students expected to search iteratively, continuously modifying and refining their search, rather than trying to create a perfect initial search statement. Use of the browser's back button in MetaLib causes unpredictable results, preventing students from using navigation patterns they are accustomed to using elsewhere on the Internet. Nearly all students repeated their searches, changing terms or subject categories, so the interface needs to make this easy. One way this might be achieved is by placing a search box on the search results screen. Other displays of search results, such as clustering and faceted browsing would offer users ways to review results and discover other records.

Students expected to be able to discern the relevance of search results from the results list. They found the information displayed in the MetaLib table view results list to be lacking key pieces of information. For example, one of the students' concerns was determining whether an item was scholarly or peer-reviewed. Displaying the journal or book name on the results list would be one way of making this determination easier. One student said, while looking at the results list, "I would have to search through every single one of these to find which one is a scholarly article and which one is just a newspaper article." Students found abstracts useful and expressed the desire to see this information on the results list as well. While space limitations would make displaying the full abstract in the results list unwieldy, showing keywords in context, as Google and other search engines do, could be one approach. Reliable relevance ranking would be another means of helping students find useful articles and books more quickly. While students usually realized that Research Port was sorting results by date, they expressed the desire to have relevance ranking.

\section{Conclusions}

In this study, students perceived metasearch to be a useful tool. However, aspects of functionality and interface design contributed to low rates of success in completing tasks. Students expect to search metasearch interfaces the same way they search Internet search engines, but the underlying technology does not yet make this possible. Unlike search engines such as Google, which nearly instantaneously searches a "just-in-case," preprocessed index of sites, metasearch performs a "just-in-time" search, connecting with multiple remote resources and aggregating a subset of results from each at the time of the search. The metasearch process can take much longer than Google, and discovering results from disparate 
resources can present technical and usability challenges. Improving the design of search screens and the display of results lists would help increase students' success in completing tasks.

The test questions asked students to look for two items that would be relevant for their topic. However, students sometimes said they had completed a task when they had only identified one item as being useful. The think-aloud protocol may have distracted the students, and, in a future test, requiring participants to locate one resource might provide more reliable task completion rates. In future testing, allowing students to choose which search interface to use, Quick Search or Cross Search, might elicit more information about student preferences in metasearch search options.

Further areas of research include iterative testing of design changes suggested above. Since this study, USMAI changed the Quick Search and Cross Search screens to offer more guidance in the formation of search statements. The basic, single search box option has been removed and the screens instead display the Advanced search screen, which offers two fields and dropdown menus indicating which field is being searched. The names and distribution of subject categories could also be further reviewed. Features such as faceted browsing or clustering of search results are planned for future versions of MetaLib and should be tested with students. (MetaLib version 4.0, released in spring 2007, includes these options.) Other further usability testing with user groups such as new undergraduate students, graduate students, and faculty would be worthwhile.

Students recognized that libraries resources were valuable, useful, and appropriate resources for their classes. All of them said they already use the library Web site to work on class projects. Yet, they find Google, Yahoo, and other search engines easier to use and turn to those when their searches fail at the library. Metasearch interfaces were intended to offer an easy-to-use, search engine-like interface. Nonetheless, technical limitations on metasearch continue to prevent those systems from searching and processing results as quickly and as effectively as Internet search engines. ${ }^{18}$ Librarians might approach these challenges as an opportunity for discussion and instruction. ${ }^{19}$ By conducting further usability testing and improving metasearch interfaces, libraries can help students have more success in using metasearch, which the students appear ready to accept. 


\section{Appendix A: Coding Structure}

\begin{tabular}{|c|c|}
\hline \multicolumn{2}{|r|}{ Quick Search } \\
\hline $\begin{array}{c}\text { Code } \\
\text { Number }\end{array}$ & Code Name \\
\hline \multicolumn{2}{|r|}{ 1.0 Perceptions } \\
\hline 1.1 & Expected to be able to discern format type (article or book) \\
\hline 1.2 & Assumed results list sorted by date \\
\hline 1.3 & Expected large results list \\
\hline 1.4 & Expected small results list \\
\hline 1.5 & Assumed results list sorted by relevance \\
\hline 1.6 & Assumed results list sort by database \\
\hline 1.7 & Did not perceive any order to results list \\
\hline 1.8 & Perceived recent items as more useful \\
\hline 1.9 & $\begin{array}{l}\text { Expected to be able to discern scholarly and nonscholarly items from results } \\
\text { display }\end{array}$ \\
\hline 1.10 & Expected full-text available through title link \\
\hline 1.11 & Expected full-text always available through Find It \\
\hline 1.12 & Assumed full-text sometimes (not always) available through Find It \\
\hline 1.13 & $\begin{array}{l}\text { Perceived that continuing to use metasearch will not help them complete the } \\
\text { task; would go to alternative resources (Internet or librarian) }\end{array}$ \\
\hline 1.14 & Perceived speed that results returned as reasonable \\
\hline 1.15 & Perceived speed that results returned as too slow \\
\hline 1.0 .1 & Perceived QS is for simple/broad searches \\
\hline 1.0 .2 & Perceived QS simultaneously searches multiple databases \\
\hline 1.0 .3 & Perceived QS is a research starting point \\
\hline 1.0 .4 & Perceived QS is a fast search (i.e., executed quickly) \\
\hline 1.0 .5 & Assumed QS searches the Internet \\
\hline \multicolumn{2}{|r|}{ 2.0 Searching \& Navigation } \\
\hline 2.1 & Used Boolean Operators \\
\hline 2.2 & $\begin{array}{l}\text { Entered search statement as a string of words and/or phrases describing mul- } \\
\text { tiple concepts }\end{array}$ \\
\hline 2.3 & Used operators or wild cards not supported by MetaLib \\
\hline 2.4 & Commented on Advanced Search tab but did not use it \\
\hline 2.5 & Used Advanced Search \\
\hline 2.6 & Modified search from specific to broad \\
\hline 2.7 & Modified search from broad to specific \\
\hline 2.8 & Used Refine page \\
\hline 2.9 & Used search link or tab in toolbar \\
\hline
\end{tabular}


Usability Testing of a Metasearch Interface 305

\begin{tabular}{|c|c|}
\hline 2.10 & Clicked on previous searches link in toolbar \\
\hline 2.11 & Used results list link to navigate among results \\
\hline 2.12 & Used browser "Back" button to return to search screen from results list \\
\hline 2.13 & $\begin{array}{l}\text { Used Previous or Next or browser "Back" and given unexpected results when } \\
\text { navigating among results list views (table, brief, full record) }\end{array}$ \\
\hline 2.14 & Used Find It button \\
\hline 2.15 & Used brief view \\
\hline 2.16 & Clicked on link to database from results list or full record \\
\hline 2.0 .1 & Clicked database name on list of database in QS \\
\hline & 3.0 Design and Display of Information \\
\hline 3.1 & Desired that results list sort by relevance \\
\hline 3.2 & Disliked presence of duplicate items \\
\hline 3.3 & Liked presence of year in results table view \\
\hline 3.4 & Liked presence of title in results table view \\
\hline 3.5 & Liked highlighted search terms in results list \\
\hline 3.6 & Desired that results list display abstract \\
\hline 3.7 & Desired that results list display journal name in table view \\
\hline 3.8 & Desired length of article/book on results list table view \\
\hline 3.9 & Desired that results list display format in table view \\
\hline 3.10 & Desired full-text link at results table view \\
\hline 3.11 & Liked presence of journal name in brief view \\
\hline 3.12 & Liked presence of title in brief view \\
\hline 3.13 & Desired language information \\
\hline 3.14 & Desired full-text link at brief view \\
\hline 3.15 & Desired full-text (or portion of it) available at brief view \\
\hline 3.16 & Desired definition of CS and QS on interface \\
\hline 3.17 & Found that some information on full record view was unnecessary or unclear \\
\hline 3.18 & Liked presence of abstract \\
\hline 3.19 & Desired full-text in full record view \\
\hline 3.20 & Expressed that save icon on full view unclear \\
\hline 3.21 & Desired search box on every screen \\
\hline 3.22 & Expressed that error message was unclear \\
\hline 3.23 & Desired spellcheck functionality in search \\
\hline 3.24 & Made positive comment on Refine link in toolbar \\
\hline 3.25 & Expressed need to refine search and was unable to determine how \\
\hline 3.26 & Made positive comment about Find It \\
\hline 3.27 & Made negative comment about Find It \\
\hline 3.28 & $\begin{array}{l}\text { Expressed that multiple windows generated by Find It and database links were } \\
\text { confusing/annoying }\end{array}$ \\
\hline
\end{tabular}




\begin{tabular}{|c|c|}
\hline 3.29 & $\begin{array}{l}\text { Expressed that there were too many steps to get what was needed (too much } \\
\text { clicking) }\end{array}$ \\
\hline 3.30 & Expressed that e-mail action icon useless \\
\hline 3.31 & Made positive comment about e-mail functionality \\
\hline 3.32 & Made positive comment about a native interface of another database \\
\hline 3.0 .1 & Made positive comment about QS interface \\
\hline 3.0 .2 & Made negative comment about QS interface \\
\hline \multicolumn{2}{|r|}{ Cross Search } \\
\hline $\begin{array}{l}\text { Code } \\
\text { Number }\end{array}$ & Code Name \\
\hline \multicolumn{2}{|r|}{ 1.0 Perceptions } \\
\hline 1.1 & Expected to be able to discern format type (article or book) \\
\hline 1.2 & Assumed results list sorted by date \\
\hline 1.3 & Expected large results list \\
\hline 1.4 & Expected small results list \\
\hline 1.5 & Assumed results list sorted by relevance \\
\hline 1.6 & Assumed results list sorted by database \\
\hline 1.7 & Did not perceive any order to results list \\
\hline 1.8 & Perceived recent items as more useful \\
\hline 1.9 & $\begin{array}{l}\text { Expected to be able to discern scholarly and nonscholarly items from results } \\
\text { display }\end{array}$ \\
\hline 1.10 & Expected full-text available through title link \\
\hline 1.11 & Expected full-text always available through Find It \\
\hline 1.12 & Assumed full-text sometimes (not always) available through Find It \\
\hline 1.13 & $\begin{array}{l}\text { Perceived that continuing to use metasearch will not help them complete the } \\
\text { task; would go to alternative resources (Internet or librarian) }\end{array}$ \\
\hline 1.14 & Perceived speed that results returned as reasonable \\
\hline 1.15 & Perceived speed that results returned as too slow \\
\hline 1.0 .1 & Perceived that CS searches multiple databases within a subject category \\
\hline 1.0 .2 & Expected to be able to search multiple categories and/or subcategories \\
\hline 1.0 .3 & Assumed CS provides more search complexity \\
\hline 1.0 .4 & Assumed that CS provides less search complexity \\
\hline 1.0 .5 & Assumed that CS is for searching on broad topics \\
\hline 1.0 .6 & Could not perceive a purpose for CS \\
\hline \multicolumn{2}{|r|}{ 2.0 Searching \& Navigation } \\
\hline 2.1 & Used Boolean Operators \\
\hline 2.2 & $\begin{array}{l}\text { Entered search statement as a string of words and/or phrases describing mul- } \\
\text { tiple concepts }\end{array}$ \\
\hline 2.3 & Used operators or wild cards not supported by MetaLib \\
\hline
\end{tabular}


Usability Testing of a Metasearch Interface 307

\begin{tabular}{|c|c|}
\hline 2.4 & Commented on Advanced Search tab but did not use it \\
\hline 2.5 & Used Advanced Search \\
\hline 2.6 & Modified search from specific to broad \\
\hline 2.7 & Modified search from broad to specific \\
\hline 2.8 & Used Refine page \\
\hline 2.9 & Used search link or tab in toolbar \\
\hline 2.10 & Clicked on previous searches link in toolbar \\
\hline 2.11 & Used results list link to navigate among results \\
\hline 2.12 & Used browser "Back" button to return to search screen from results list \\
\hline 2.13 & $\begin{array}{l}\text { Used Previous or Next or browser "Back" and given unexpected results when } \\
\text { navigating among results list views (table, brief, full record) }\end{array}$ \\
\hline 2.14 & Used Find It button \\
\hline 2.15 & Used brief view \\
\hline 2.16 & Clicked on link to database from results list or full record \\
\hline 2.0 .1 & Selected subject category \\
\hline 2.0 .2 & Selected subcategory within subject category \\
\hline 2.0 .3 & Changed subject category or subcategory \\
\hline 2.0 .4 & Did not select subject category \\
\hline 2.0 .5 & Clicked on link to database on CS search screen \\
\hline \multicolumn{2}{|r|}{ 3.0 Design and Display of Information } \\
\hline 3.1 & Desired that results list sort by relevance \\
\hline 3.2 & Disliked presence of duplicate items \\
\hline 3.3 & Liked presence of year in results table view \\
\hline 3.4 & Liked presence of title in results table view \\
\hline 3.5 & Liked highlighted search terms in results list \\
\hline 3.6 & Desired that results list display abstract \\
\hline 3.7 & Desired that results list display journal name in table view \\
\hline 3.8 & Desired length of article/book on results list table view \\
\hline 3.9 & Desired that results list display format in table view \\
\hline 3.10 & Desired full-text link at results table view \\
\hline 3.11 & Liked presence of journal name in brief view \\
\hline 3.12 & Liked presence of title in brief view \\
\hline 3.13 & Desired language information \\
\hline 3.14 & Desired full-text link at brief view \\
\hline 3.15 & Desired full-text (or portion of it) available at brief view \\
\hline 3.16 & Desired definition of CS and QS on interface \\
\hline 3.17 & Found that some information on full record view is unnecessary or unclear \\
\hline 3.18 & Liked presence of abstract \\
\hline 3.19 & Desired full-text in full record view \\
\hline
\end{tabular}




\begin{tabular}{|l|l|}
\hline 3.20 & Expressed that save icon on full view unclear \\
\hline 3.21 & Desired search box on every screen \\
\hline 3.22 & Expressed that error message unclear \\
\hline 3.23 & Desired spellcheck functionality in search \\
\hline 3.24 & Made positive comment on Refine link in toolbar \\
\hline 3.25 & Expressed need to refine search and unable to determine how \\
\hline 3.26 & Made positive comment about Find It \\
\hline 3.27 & Made negative comment about Find It \\
\hline 3.28 & $\begin{array}{l}\text { Expressed that multiple windows generated by Find It and database links } \\
\text { confusing/annoying }\end{array}$ \\
\hline 3.29 & $\begin{array}{l}\text { Expressed that there are too many steps to get what is needed (too much click- } \\
\text { ing) }\end{array}$ \\
\hline 3.30 & Expressed that e-mail action icon useless \\
\hline 3.31 & Made positive comment about e-mail functionality \\
\hline 3.32 & Made positive comment about a native interface of another database \\
\hline 3.0 .1 & Liked ability to choose subject categories \\
\hline 3.0 .2 & Expressed that left column labels unclear \\
\hline 3.0 .3 & Liked ability to select/deselect databases within subject category \\
\hline 3.0 .4 & Expressed confusion over subcategory names and/or which to select \\
\hline
\end{tabular}




\section{Appendix B: Usability Test Questions}

\section{Quick Search}

\section{Question 1}

You're taking English 101 and need to write a short paper about a controversial issue. You've decided to write about the pros and cons of school uniforms in public schools.

Find two resources that you think would help you learn about the issue.

\section{Question 2}

Please choose ONE of the following scenarios to answer.

\section{Scenario \#1}

Your biology professor has assigned a mid-semester position paper. She has given you a list of "hot topics" in the sciences to choose from. You've decided to write about the recent debate over genetically modified foods. Your professor requires that you use articles, books, and other materials in your paper to back up your position.

\section{Find two resources on your topic.}

\section{Scenario \#2}

In your American Literature class you are studying post-modern writers of the 20th century. You are to turn in a three-page essay on a writer of your choice that focuses on the author's writing style and most notable works. You've decided to write about Thomas Pynchon.

\section{Find two books on your topic.}

\section{Scenario \#3}

In your International Business class you've been assigned a research paper on American corporate outsourcing operations in Asian free trade zones. You are required to focus your paper on a specific country or a specific industry.

\section{Find two articles on your topic.}

\section{Cross Search}

\section{Question 1}

You've been assigned to write an essay on the following topic:

Is nuclear power a viable option for meeting the world's energy needs? Describe the advantages and disadvantages of the technology, including issues such as safety, environmental impact, cost, and security. 1

Find two articles or books on this topic.

\section{Question 2}

Please choose ONE of the following scenarios to answer. 


\section{Scenario \#1}

What was the Cold War? Why and when did it start? How did the Cold War affect U.S. foreign and domestic policy from the end of the Second World War to the 1990s.

Find two articles or books that would help you write a paper on this topic.

\section{Scenario \#2}

Discuss the role of religion in the creation of monuments of art from the Paleolithic through the Gothic period. You might consider the pyramids of Egypt, Greek and Roman architecture and sculpture, and Romanesque and Gothic cathedrals.

Find two resources that would help you write a paper on this topic.

\section{Scenario \#3}

Describe the causes of the Great Depression in the 1930s and explain how Franklin Roosevelt's New Deal program attempted to solve the economic crisis. Describe the goals and results of specific New Deal programs, such as the Civilian Conservation Crops and Works Progress Administration.

Find two articles or books that would help you write a paper on this topic.

\section{Expand Your Library -}

\section{Rittemhouse Book Distributors presents}

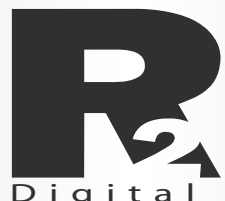

L i b r a ry

The R2 Digital Library offers a unique model for health science digital content enabling you to select and purchase only the resources you need. -

For more information and to start your free 30-day trial today, visit www.r2library.com 


\section{Notes}

1. Tamar Sadeh, "Google Scholar Versus Metasearch Systems," High Energy Physics Libraries Webzine 12 (2006). Available online from http://library.cern.ch/HEPLW/12/papers/1/. [Accessed 1 September 2006].

2. Jennifer Ward and Steve Hiller, “Usability Testing, Interface Design, and Portals,” Journal of Library Administration 43, no. 1/2 (2005): 155-71; Galina Letnikova, "Usability Testing of Academic Library Web Sites: A Selective Annotated Bibliography," Internet Reference Services Quarterly 8, no. 4 (2003): 53-68.

3. Elaina Norlin and CM! Winters, Usability Testing for Library Web Sites: A Hand-on Guide (Chicago: American Library Association, 2002).

4. Annie Armstrong, Steve Brantley, and Krystal M. Lewis, "Usability Testing of a Customizable Library Web Portal," College E Research Libraries 67, no. 2 (2006): 146-63.

5. Susan Augustine and Courtney Greene, "Discovering How Students Search a Library Web Site: A Usability Case Study," College E Research Libraries 63, no. 4 (2002): 354-65.

6. Elizabeth Stephan, Daisy T. Cheng, and Lauren M. Young, "A Usability Study at the University of Mississippi Libraries for the Improvement of the Library Homepage," Journal of Academic Librarianship 32, no. 1 (2006): 35-51.

7. Leanne M. VandeCreek, "Usability Analysis of Northern Illinois University Libraries' Website: A Case Study," OCLC Systems E Services 21, no. 3 (2005): 181-92.

8. Susan Elliott, Metasearch and Usability: Toward a Seamless Interface to Library Resources (August 2004). Available online from www.lib.uaa.alaska.edu/tundra/msuse1.pdf. [Accessed 19 October 2004].

9. Ibid.

10. Bob Gerrity, Theresa Lyman, and Ed Tallent, "Blurring Services and Resources: Boston College's Implementation of Metalib and Sfx," Reference Services Review 30, no. 3 (2002): 229-41. 11. Ibid.

12. Ed Tallent, "Metasearching in Boston College Libraries - a Case Study of User Reactions," New Library World 105, no. 1196/1197 (2004): 69-75.

13. Norlin and Winters, Usability Testing for Library Web Site.

14. M.J. Van den Haak, M.D.T. de Jong, and P.J. Schellens, "Employing Think-Aloud Protocols and Constructive Interaction to Test the Usability of Online Library Catalogues: A Methodological Comparison," Interacting with Computers 16, no. 6 (2004): 1153-70.

15. Jakob Nielsen, "Why You Only Need to Test with 5 Users," Alertbox (March 19, 2000). Available online from www.userit.com/alertbox/20000319.html. [Accessed 7 August 2006].

16. Judy Jeng, "What Is Usability in the Context of the Digital Library and How Can It Be Measured?," Information Technology in Libraries 24, no. 2 (2006): 47-56.

17. G.E. Gorman and Peter Clayton, Qualitative Research for the Information Professional: A Practical Handbook, 2nd ed. (London: Facet Publishing, 2005).

18. Marshall Breeding, "Plotting a New Course for Metasearch," Computers in Libraries 25, no. 25 (2005): 27-30.

19. Christopher Cox, "An Analysis of the Impact of Federated Search Products on Library Instruction Using the ACRL Standards," portal: Libraries and the Academy 6, no. 3 (2006): 253-67. 